University of Massachusetts Amherst

ScholarWorks@UMass Amherst

Civil and Environmental Engineering Faculty

Publication Series

Civil and Environmental Engineering

2018

\title{
A multi-variable equation for relationship between limiting void ratios of uniform sands and morphological characteristics of their particles
}

\author{
Ching S. Chang \\ University of Massachusetts Amherst \\ Yibing Deng \\ University of Massachusetts Amherst \\ Mehrashk Meidani \\ Group Delta Consultants, Inc.
}

Follow this and additional works at: https://scholarworks.umass.edu/cee_faculty_pubs

\section{Recommended Citation}

Chang, Ching S.; Deng, Yibing; and Meidani, Mehrashk, "A multi-variable equation for relationship between limiting void ratios of uniform sands and morphological characteristics of their particles" (2018).

Géotechnique Letters. 848.

https://doi.org/10.1016/j.enggeo.2018.02.003

This Article is brought to you for free and open access by the Civil and Environmental Engineering at ScholarWorks@UMass Amherst. It has been accepted for inclusion in Civil and Environmental Engineering Faculty Publication Series by an authorized administrator of ScholarWorks@UMass Amherst. For more information, please contact scholarworks@library.umass.edu. 


\title{
A multi-variable equation for relationship between limiting void ratios of uniform sands and morphological characteristics of their particles
}

\author{
Ching S. Chang ${ }^{\mathrm{a}, *}$, Yibing Deng ${ }^{\mathrm{a}}$, Mehrashk Meidani ${ }^{\mathrm{b}}$ \\ a Department of Civil and Environmental Engineering, University of Massachusetts, Amherst, MA 01003, United States \\ ${ }^{\mathrm{b}}$ Group Delta Consultants, Inc., Irvine, CA 92618, United States
}

\section{A R T I C L E I N F O}

\section{Keywords:}

Particle size

Particle shape

Minimum void ratio

Maximum void ratio

Sand

Multivariable analysis

\begin{abstract}
A B S T R A C T
The limiting void ratios (i.e., the minimum and the maximum void ratios) are two important index properties, which are related to the compressibility, shear strength, and permeability of granular soils. Experimental studies have shown that the limiting void ratios are correlated to morphological properties of soil particles (i.e. particle size and particle shape). However, empirical equations available in literature for the limiting void ratios are generally single-variable functions of either particle size, or particle shape. In this study, we propose multivariable equations, in which the limiting void ratios are functions of both particle size and particle shape. The coupled effects of particle size and particle shape on the limiting void ratios are illustrated. Advantages of the proposed multi-variable equations over the existing single-variable equations are shown by comparing the calculated void ratios with the experimental data on a large number of uniform sand samples. The proposed multi-variable equations can be applied to predict the limiting void ratios of uniform sands encountered in geotechnical engineering projects in order to properly support heavy loads.
\end{abstract}

\section{Introduction}

The limiting void ratios (i.e., the minimum and the maximum void ratios) are two important index properties of granular soils, which are correlated to the compressibility, shear strength, and permeability (Selig and Ladd, 1973; Aberg, 1992; Miura et al., 1997; Cubrinovski and Ishihara, 2002; Bandini and Sathiskumar, 2009; Bobei et al., 2009; Peters and Berney, 2010; Belkhatir et al., 2013; Fuggle et al., 2014). Experimental studies have shown that the limiting void ratios are functions of particles morphological characteristics, specifically, the particle size and particle shape (Youd, 1973; Miura et al., 1997; Santamarina and Cho, 2004; Cho et al., 2006; Rouse et al., 2008; Rout, 2009; Patra et al., 2010; Zheng and Hryciw, 2016). These two morphological characteristics, i.e. particle size and particle shape, are dependent on the lithology, transportation history, and deposition environment of the soil. Therefore, the limiting void ratios vary from site to site.

For the two morphological characteristics, particle size is usually measured by a standard sieve analysis. Particle shape, however, has several types of measures, which are roundness, sphericity, aspect ratio, and roughness (Barrett, 1980; Diepenbroek et al., 1992; Hyslip and Vallejo, 1997; Cox and Budhu, 2008; Tafesse et al., 2012; Uday et al., 2013; Okonta, 2015). Roundness measures the sharpness of particles' edges, whereas sphericity and aspect ratio measure the overall shape of the particles. Roughness describes the surface texture of the particles. In geotechnical engineering literature, roundness is the most commonly used parameter to describe the shape of sand particles.

It is important to have a mathematical expression for the relationship between the minimum or maximum void ratio of sands and morphological characteristics of their particles, because it is a steppingstone for understanding the relationship between particle morphology and mechanical properties of soils such as shear strength, compressibility, and permeability.

The correlation between particle size and limiting void ratio of granular soil has been investigated in several experimental studies. Miura et al. (1997) examined natural and reconstituted sands, and concluded that the minimum void ratio $\left(e_{\min }\right)$ and the maximum void ratio $\left(e_{\max }\right)$ tend to decrease with increase of mean particle size. Cubrinovski and Ishihara (2002) and Bareither et al. (2008) observed the same tendency for clean sands, and for sands with some fines. Rout (2009) and Patra et al. (2010) proposed an empirical equation for the two limiting void ratios as functions of mean particle size $D_{50}$.

The correlation between particle shape and the limiting void ratio of granular soil has been extensively investigated as well. A number of empirical equations have been proposed by several researchers for the two limiting void ratios as functions of particle roundness (Youd, 1973;

\footnotetext{
* Corresponding author.

E-mail addresses: chang@ecs.umass.edu (C.S. Chang), yibingdeng@engin.umass.edu (Y. Deng), mehrashkm@groupdelta.com (M. Meidani).
} 
Shimobe and Moroto, 1995; Santamarina and Cho, 2004; Cho et al., 2006; Rouse et al., 2008; Zheng and Hryciw, 2016).

Two shortcomings can be identified in the previous studies:

(1) The effect of particle size distribution (PSD) was not separated from the effect of particle morphological characteristics on the limiting void ratio, particularly, in the studies of the correlations between particle size and the limiting void ratio. The samples used were not uniformly graded, sometimes the samples were mixtures of sand and fines.

(2) The coupling effect of particle size and particle shape variation on the limiting void ratios was neglected by only considering a singlevariable in the equations. The empirical equations for the two limiting void ratios are functions of either particle size or particle shape. They were obtained from single-variable regression analysis. However, in general, the limiting void ratios are influenced simultaneously by both particle size and particle shape.

To overcome the first shortcoming, we eliminate the effect of PSD of soil samples by using uniform sand samples. In this study, we generate a database obtained from test results in the literature on very narrowly graded sand samples.

To overcome the second shortcoming, we conduct a multi-variable analysis by considering particle size and particle shape as two separate variables. The limiting void ratio $\left(e_{\min }\right.$ or $\left.e_{\max }\right)$ is considered to be the outcome variable, and the particle size and particle shape are considered to be predictor variables.

In this study, we aim to establish multi-variable equations for the two limiting void ratios as functions of particle size and particle roundness. Using the collected database, the correlations between the predictor variables and the outcome variables are derived to show the relative influence of particle size and particle shape on the two limiting void ratios. Based on the multi-variable analysis, we propose mathematical expressions for the two limiting void ratios $\left(e_{\min }\right.$ and $\left.e_{\max }\right)$ as functions of particle size and particle roundness. The advantage of the proposed equations is demonstrated by comparing the predicted limiting void ratios with those predicted by the existing single-variable equations.

The proposed multi-variable equations can be directly applied to predict the limiting void ratios of uniform sands encountered in geotechnical engineering projects. For soil with a broader range of particle sizes, the equations proposed in this study can be used together with analytical packing models (e.g. Chang et al., 2015, 2017; De Larrard, 1999; Yu and Standish, 1988) for an estimation of the limiting void ratios of multi-sized particle packings.

\section{Measurement methods for the limiting void ratios and morphological characteristics of sand particles}

The values of $e_{\min }$ and $e_{\max }$ can be measured by the commonly used procedures specified in standard tests such as those in American Society for Testing and Materials (ASTM D4253-00, 2006; ASTM D4254-00, 2006), or in Japanese Geotechnical Society (2000). Several other methods are also available in literature to determine the two limiting void ratios (Kolbuszewski, 1948; Mulilis et al., 1977; Vaid and Negussey, 1988). These methods may provide slightly different values for the two limiting void ratios (Blaker et al., 2015; Tavenas et al., 1973).

Particle size can be expressed as its equivalent spherical diameter obtained from the sieve analysis procedure (ASTM D422-63, 2007). The size of particles between the two adjacent sieves is determined by averaging the opening size of two sieves. It is noted that the measured particle size from sieve analysis is only an approximation, since the particles are not spherical and their sizes are in the range between the

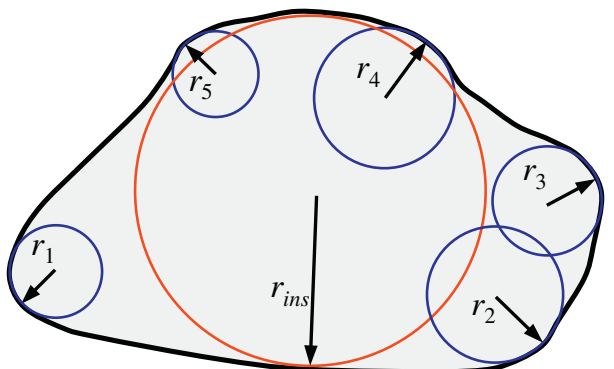

Fig. 1. Geometric parameters used in the definition of roundness $(R)$.

sieves intervals (Allen, 1997).

Particle shape can be quantified by several methods. In soil mechanics and engineering geology fields, roundness is the most commonly used measure for quantification of particle shape characteristics. However, there is no institutional standard for its measurement.

Roundness (R), as defined by Wadell (1935), is the ratio of the average radius of curvature of the particle edges to the radius of the maximum inscribed circle:

$R=\frac{\frac{1}{n} \sum_{i=1}^{n} r_{i}}{r_{i n s}}$

where $n$ is the total number of corners, $r_{i}$ is the radius of circle fitting the $i$ th corner, and $r_{i n s}$ is the radius of inscribed circle, as shown in Fig. 1.

The roundness determined from Eq. (1) is not unique because it is obtained based on an arbitrary two-dimensional projected image of the particle, and it is also subjective to the determined size of the circles fitting the corners. Krumbein (1941) and Powers (1953) developed roundness estimation charts consisting of a set of reference particle silhouettes, as shown in Fig. 2a and b. This guide was prepared to facilitate rapid estimation of Wadell's particle roundness through visual comparison. These charts are used in many disciplines including geotechnical engineering, soil science, agriculture, powder engineering, and geology. It is obvious that, similar to particle size, roundness is also an approximate way to describe the shape of particles.

\section{Database of particle size, particle roundness and limiting void} ratios for 26 types of uniform sand

A collection of sand particles can be regarded as uniform sand when its coefficient of uniformity $C_{u}$ is smaller than 2.5 (see Cho et al. (2006), Rouse et al. (2008) and Youd (1973)). Based on this criterion, the data listed in Table 1 are for 26 types of uniform sands collected from different locations around the world (Youd, 1973; Edil et al., 1975; Norris, 1977; Cho et al., 2006; Rouse et al., 2008). We also include our own measurements for the Plymouth beach sand, Massachusetts. For the sands listed in Table 1, the range of mean particle size is from $0.096 \mathrm{~mm}$ to $3.082 \mathrm{~mm}$. The range of particle roundness is from 0.17 to 1 . The range of $C_{u}$ is from 1.1 to 2.4. Fig. 3 shows the ranges of $D_{50}, R$ and $C_{u}$ for the sand samples listed in Table 1 .

4. The existing single-variable equations for relationship between the limiting void ratios and particle size

Rout (2009) and Patra et al. (2010) proposed an empirical equation for relationship between the limiting void ratios and the mean particle size $\left(D_{50}\right)$ in the following form:

$e_{\lim }=b\left(D_{50}\right)^{\lambda}$ 


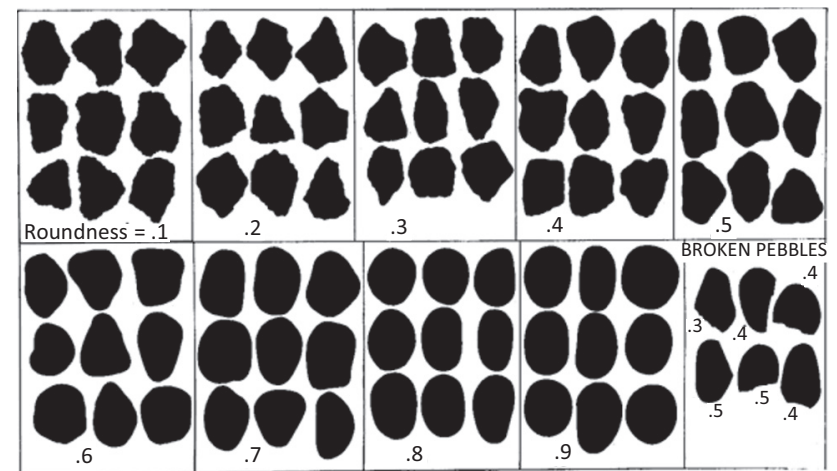

(a) Krumbein's roundness visual chart (Krumbein, 1941)

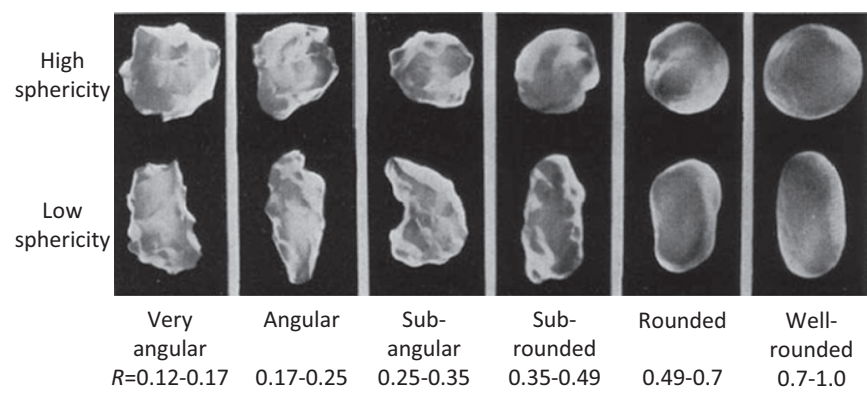

(b) Powers' roundness visual chart (Power, 1953)

Fig. 2. Visual comparison charts for roundness: (a) Krumbein (1941); (b) Powers (1953).

where $e_{\text {lim }}$ is the limiting void ratio (either $e_{\min }$ or $e_{\max }$ ), and $b$ and $\lambda$ are the model parameters, which take different values for the cases of minimum and maximum void ratios. Patra et al. (2010) obtained the values of $b$ and $\lambda$ from test results on uniform and non-uniform sands from 10 rivers in India. The coefficient of uniformity of these sand samples ranges from 1.42 to 9.83 . Based on these samples, they determined the following equations for the limiting void ratios:

$e_{\min }=0.33\left(D_{50}\right)^{-0.49} ; e_{\max }=0.60\left(D_{50}\right)^{-0.30}$

Fig. 4 shows the predicted limiting void ratios by these two equations compared with the test results used by Patra et al. (2010). The coefficient of determination $\mathrm{R}^{2}=0.76$ for $e_{\max }$, and $\mathrm{R}^{2}=0.85$ for $e_{\min }$.

In order to filter out the effect of gradation on the limiting void ratios, we use the test data from uniform sands (Table 1) and determine a new set of parameters for Eq. (2) through the best-fit process. The new values of $b$ and $\lambda$ are determined and shown in the following equations:

$e_{\min }=0.50\left(D_{50}\right)^{-0.11} ; e_{\max }=0.79\left(D_{50}\right)^{-0.13}$

Fig. 5 shows the newly predicted limiting void ratios with solid lines using Eq. (4). Eq. (3) is also used to predict the limiting void ratios for the selected uniform sands and the results are shown with dashed lines. The test data from Table 1 are shown by symbols.

It is obvious from Fig. 5 that both solid and dashed lines are in poor agreement with the data from Table 1 . The use of a larger database of uniform sand samples can evaluate the applicability of an empirical equation more accurately. Therefore, Eq. (2) proposed by Patra et al. (2010) is shown to not be a suitable predictive equation for the limiting void ratios.

5. The existing single-variable equations for relationship between the limiting void ratios and particle roundness

Several researchers have sought to correlate the particle roundness to the limiting void ratios and proposed empirical equations. For example, Shimobe and Moroto (1995) proposed an equation based on the tests results in their database, in which, most samples are uniform sand, but a few samples are mixture of sand and glass beads, which are not uniformly graded. The proposed equation is for maximum void ratio as a function of particle roundness $R$ :

$e_{\max }=0.64(R)^{-0.354}$

Santamarina and Cho (2004) proposed a hyperbolic equation for relationship between particle roundess $R$ and the limiting void ratios, using the test data from Youd (1973), which included eight samples from natural and crushed unform sands. The proposed two equations are as follows:

$e_{\min }=0.359+0.082(R)^{-1} ; e_{\max }=0.554+0.154(R)^{-1}$

Cho et al. (2006) proposed a simple linear equation for relationship between particle roundess $R$ and the limiting void ratios, using 19 samples for $e_{\max }$ and 16 samples for $e_{\min }$ from natural and crushed uniform sands. The derived equations are as follows:

$e_{\min }=0.80-0.34 R ; e_{\max }=1.30-0.62 R$

Rouse et al. (2008) used the same hyperbolic equation proposed by Santamarina and Cho (2004), but the database they used were larger than that used by Santamarina and Cho (2004). In addition to the test data from Youd (1973), their database includes additional samples of sand, glass beads, and gravel. It is comprised of 66 samples for $e_{\max }$ and 46 samples for $e_{\min }$. All samples are uniformly graded. The derived equations are:

$e_{\min }=0.433+0.051(R)^{-1} ; e_{\max }=0.615+0.107(R)^{-1}$

Fig. 6 shows the prediction from Eqs. (5) to (8) in dashed lines. The prediction results are compared with the test data shown by symbols. The predictions are in good agreement with the measured void ratios.

We use the data in Table 1 to determine new sets of coefficients for Eqs. (5) to (8) through best-fit process. The following new coefficients are determined.

Using the equation proposed by Shimobe and Moroto (1995) in Eq. (5), the following equations are determined:

$e_{\min }=0.43(R)^{-0.28} ; e_{\max }=0.65(R)^{-0.36}$

Using the equations proposed by Santamarina and Cho (2004) and Rouse et al. (2008) in Eqs. (6) and (8), the following equations are determined:

$e_{\min }=0.39+0.06(R)^{-1} ; e_{\max }=0.56+0.13(R)^{-1}$

The linear equation by Cho et al. (2006) in Eq. (7) takes new coefficients as follows:

$e_{\min }=0.71-0.33 R ; e_{\max }=1.24-0.71 R$

Eqs. (9) to (11) are plotted in Fig. 7 with solid lines. For comparison, the test data from Table 1 are shown by symbols and Eqs. (5) to (8) are plotted with dashed lines. The deviation between the solid lines and dash lines are due to the difference in the selected databases. The discrepancy is larger for Eq. (7) proposed by Cho et al. (2006), whereas the discrepancies for the other three equations are relatively small. Comparing the coefficients of determination $\mathrm{R}^{2}$ shows that predictions by Eq. (10) have the best agreement with the measured void ratios.

Fig. 7 shows that the single-variable equations with roundness as a predictive variable are suitable to predict void ratio from a larger database, whereas Fig. 5 showed that the single-variable equations with particle size as a predictive variable are not suitable.

6. Proposed multi-variable equation for the limiting void ratio as a function of particle roundness and particle size

In this section, we construct a multi-variable equation in which the limiting void ratio $\left(e_{\min }\right.$ or $\left.e_{\max }\right)$ is the outcome variable, and mean 
Table 1

Morphological characteristics and the limiting void ratios of selected uniform sands.

\begin{tabular}{|c|c|c|c|c|c|c|c|c|}
\hline Sand type & $e_{\max }$ & $e_{\min }$ & $C_{u}$ & $D_{50}$ & $R$ & $S$ & Reference & Test method \\
\hline \multirow[t]{6}{*}{ Crushed basalt } & 1.420 & 0.803 & 1.4 & 0.096 & 0.17 & - & \multirow[t]{15}{*}{ Youd (1973) } & $e_{\max }:$ repeated straining in simple shear \\
\hline & 1.350 & 0.747 & 1.4 & 0.177 & 0.18 & - & & $e_{\min }:$ ASTM D 2049-69 \\
\hline & 1.320 & 0.692 & 1.4 & 0.354 & 0.19 & - & & \\
\hline & 1.260 & 0.705 & 1.4 & 0.707 & 0.19 & - & & \\
\hline & 1.260 & 0.722 & 1.4 & 1.414 & 0.20 & - & & \\
\hline & 1.190 & 0.700 & 1.4 & 2.828 & 0.20 & - & & \\
\hline \multirow[t]{3}{*}{ Del Monte White sand } & 1.203 & 0.636 & 1.4 & 0.096 & 0.21 & - & & \\
\hline & 1.082 & 0.55 & 1.4 & 0.177 & 0.23 & - & & \\
\hline & 0.971 & 0.503 & 1.4 & 0.354 & 0.27 & - & & \\
\hline Lapis Lustre sand & 0.754 & 0.460 & 1.4 & 2.828 & 0.44 & - & & \\
\hline \multirow[t]{2}{*}{ Monterey sand } & 0.799 & 0.458 & 1.4 & 0.707 & 0.34 & - & & \\
\hline & 0.772 & 0.469 & 1.4 & 1.414 & 0.39 & - & & \\
\hline \multirow[t]{3}{*}{ Ottawa sand } & 0.830 & 0.460 & 1.4 & 0.177 & 0.38 & - & & \\
\hline & 0.772 & 0.407 & 1.4 & 0.354 & 0.42 & - & & \\
\hline & 0.704 & 0.408 & 1.4 & 0.707 & 0.60 & - & & \\
\hline \multirow[t]{3}{*}{ Franklin Falls sand } & 1.080 & 0.620 & 1.2 & 0.714 & 0.36 & 0.82 & \multirow[t]{8}{*}{ Edil et al. (1975) } & $e_{\max }:$ the procedure suggested by Kolbuszewski (1948) \\
\hline & 1.090 & 0.630 & 1.2 & 0.421 & 0.35 & 0.81 & & $e_{\min }:$ vibratory densification technique \\
\hline & 1.100 & 0.640 & 1.2 & 0.252 & 0.34 & 0.81 & & \\
\hline \multirow[t]{5}{*}{ Ottawa sand } & 0.770 & 0.460 & 1.2 & 0.714 & 0.65 & 0.87 & & \\
\hline & 0.820 & 0.480 & 1.2 & 0.421 & 0.60 & 0.85 & & \\
\hline & 0.890 & 0.530 & 1.2 & 0.252 & 0.52 & 0.84 & & \\
\hline & 0.920 & 0.540 & 1.2 & 0.178 & 0.50 & 0.83 & & \\
\hline & 0.920 & 0.540 & 1.2 & 0.126 & 0.50 & 0.82 & & \\
\hline \multirow[t]{3}{*}{ Diagenetic sand } & 0.723 & 0.471 & 1.1 & 0.922 & 0.67 & 0.85 & \multirow[t]{9}{*}{ Norris (1977) } & $e_{\min }:$ ASTM D 2049-69 \\
\hline & 0.733 & 0.486 & 1.1 & 0.324 & 0.64 & 0.85 & & $e_{\max }:$ the procedure suggested by Kolbuszewski (1948) \\
\hline & 0.799 & 0.539 & 1.1 & 0.115 & 0.56 & 0.83 & & \\
\hline \multirow[t]{4}{*}{ Felton Beach sand } & 0.820 & 0.540 & 1.1 & 2.571 & 0.49 & 0.83 & & \\
\hline & 0.884 & 0.563 & 1.1 & 0.922 & 0.31 & 0.82 & & \\
\hline & 1.002 & 0.654 & 1.1 & 0.324 & 0.27 & 0.81 & & \\
\hline & 1.360 & 0.856 & 1.1 & 0.115 & 0.22 & 0.76 & & \\
\hline \multirow[t]{2}{*}{ Monterey Coastal dune sand } & 0.892 & 0.596 & 1.1 & 0.324 & 0.35 & 0.80 & & \\
\hline & 1.012 & 0.680 & 1.1 & 0.115 & 0.32 & 0.76 & & \\
\hline 3P3-Crushed sand & 0.950 & - & 2.2 & 0.270 & 0.20 & 0.70 & \multirow[t]{14}{*}{ Cho et al. (2006) } & $e_{\min }:$ ASTM D1557 \\
\hline 9C1-crushed sand & 0.910 & - & 2.3 & 0.520 & 0.25 & 0.70 & & $e_{\max }:$ ASTM D4254 \\
\hline ASTM $20 / 30$ sand & 0.690 & - & 1.4 & 0.60 & 0.80 & 0.90 & & \\
\hline ASTM graded sand & 0.820 & 0.500 & 1.7 & 0.350 & 0.80 & 0.90 & & \\
\hline Blasting sand & 1.025 & 0.698 & 1.9 & 0.710 & 0.30 & 0.55 & & \\
\hline Glass beads & 0.720 & 0.542 & 1.4 & 0.320 & 1.00 & 1.00 & & \\
\hline Jekyll Island sand & 1.040 & - & 1.7 & 0.170 & 0.30 & 0.85 & & \\
\hline Margart river sand & 0.870 & - & 1.9 & 0.490 & 0.70 & 0.70 & & \\
\hline Nevada sand & 0.850 & 0.570 & 1.8 & 0.150 & 0.60 & 0.85 & & \\
\hline Ottawa F-110 sand & 0.848 & 0.535 & 1.7 & 0.120 & 0.70 & 0.70 & & \\
\hline Ottawa \#20/30 sand & 0.742 & 0.502 & 1.2 & 0.720 & 0.90 & 0.90 & & \\
\hline Ponte Vedra sand & 1.070 & - & 1.4 & 0.180 & 0.30 & 0.85 & & \\
\hline sandboil sand & 0.790 & 0.510 & 2.4 & 0.360 & 0.55 & 0.70 & & \\
\hline Ticino sand & 0.990 & 0.574 & 1.5 & 0.580 & 0.40 & 0.80 & & \\
\hline \multirow[t]{2}{*}{ Badger sand } & 0.690 & 0.490 & 1.3 & 0.870 & 0.81 & 0.77 & Rouse et al. (2008) & $e_{\min }:$ ASTM D4253 \\
\hline & & & & & & & & $e_{\max }:$ ASTM D4254 \\
\hline \multirow[t]{5}{*}{ Plymouth Beach sand } & 0.661 & 0.420 & 1.54 & 3.082 & 0.54 & - & \multirow[t]{5}{*}{ Current study } & $e_{\min }:$ ASTM D4253 \\
\hline & 0.693 & 0.481 & 1.53 & 1.304 & 0.44 & - & & $e_{\max }:$ ASTM D4254 \\
\hline & 0.720 & 0.492 & 1.41 & 0.601 & 0.42 & - & & \\
\hline & 0.902 & 0.622 & 1.3 & 0.326 & 0.34 & - & & \\
\hline & 0.970 & 0.650 & 1.18 & 0.212 & 0.30 & - & & \\
\hline
\end{tabular}

Note: $C_{u}=$ coefficient of uniformity, $D_{50}=$ mean particle size $(\mathrm{mm}), R=$ roundness, $S=$ sphericity.

particle size $\left(D_{50}\right)$ and roundness $(R)$ are two predictor variables. To check the plausibility of considering the limiting void ratio as the outcome variable, we perform multi-variable analysis on the data in Table 1 and consider $\left(e_{\min }, R, D_{50}\right)$ and $\left(e_{\max }, R, D_{50}\right)$ as two sets of three-random variables.

In statistics, covariance is a measure of the joint variability of two random variables, which indicate the strength of dependency between the two random variables. We investigate the dependencies between any two of the three random variables, i.e. between $\left(e_{\text {lim }}, R\right),\left(e_{\text {lim }}, D_{50}\right)$ and $\left(R, D_{50}\right)$, by studying the covariance between these two random variables.

The covariance matrix $\Gamma$ of a three-random-variable set $(\mathbf{x}, \mathbf{y}, \mathbf{z})$ is defined as:

$$
\Gamma=\left[\begin{array}{lll}
\operatorname{Cov}(\mathbf{x}, \mathbf{x}) & \operatorname{Cov}(\mathbf{x}, \mathbf{y}) & \operatorname{Cov}(\mathbf{x}, \mathbf{z}) \\
\operatorname{Cov}(\mathbf{y}, \mathbf{x}) & \operatorname{Cov}(\mathbf{y}, \mathbf{y}) & \operatorname{Cov}(\mathbf{y}, \mathbf{z}) \\
\operatorname{Cov}(\mathbf{z}, \mathbf{x}) & \operatorname{Cov}(\mathbf{z}, \mathbf{y}) & \operatorname{Cov}(\mathbf{z}, \mathbf{z})
\end{array}\right]
$$

This matrix provides the covariance between any two of the three random variables. The covariance $\operatorname{Cov}(\mathbf{x}, \mathbf{y})$ between random variables $\mathbf{x}$ and $\mathbf{y}$ is defined by:

$\operatorname{cov}(\mathbf{x}, \mathbf{y})=\frac{\sum_{i=1}^{n}\left(x_{i}-\bar{x}\right)\left(y_{i}-\bar{y}\right)}{n-1}$

where $\bar{x}$ and $\bar{y}$ are the average of $\mathbf{x}$ and $\mathbf{y}$ variables, respectively. $n$ is the sample size. Note that the covariance matrix is symmetric with respect to its main diagonal; i.e., $\operatorname{Cov}(\mathbf{x}, \mathbf{y})=\operatorname{Cov}(\mathbf{y}, \mathbf{x}), \operatorname{Cov}(\mathbf{x}$, $\mathbf{z})=\operatorname{Cov}(\mathbf{z}, \mathbf{x})$, and $\operatorname{Cov}(\mathbf{y}, \mathbf{z})=\operatorname{Cov}(\mathbf{z}, \mathbf{y})$. 


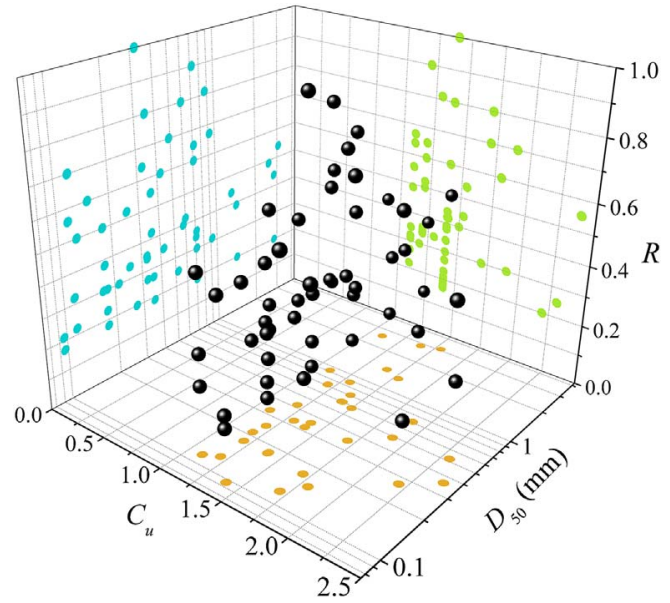

Fig. 3. The ranges of $C_{u}, D_{50}$, and $R$ for the sands selected in this study (Table 1 ).

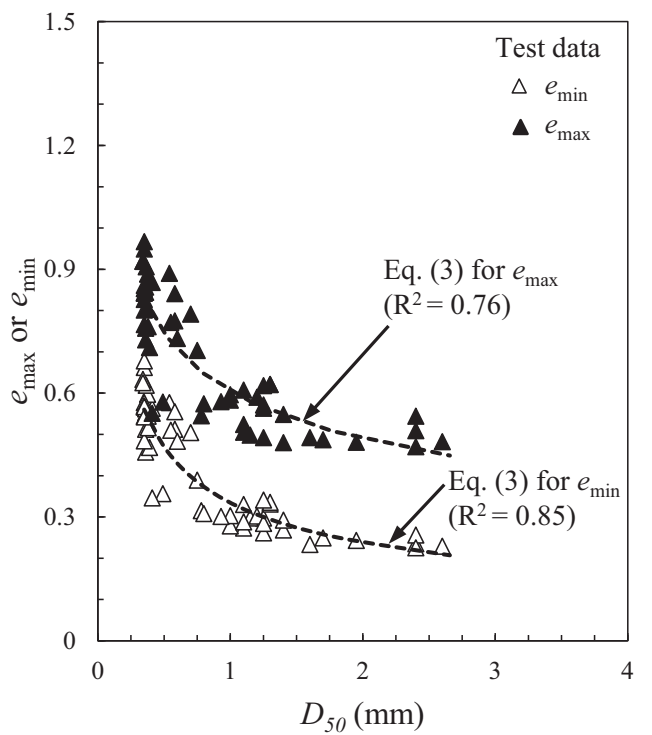

Fig. 4. Predicted limiting void ratios (dashed lines) versus mean particle size, compared with the measured values on samples with uncontrolled particle gradation (test data from Patra et al., 2010).

The covariance matrices, $\Gamma_{\min }$ of the variable set $\left(e_{\min }, R, D_{50}\right)$ and $\Gamma_{\max }$ of the variable set $\left(e_{\max }, R, D_{50}\right)$, are computed using Eqs. (12) and (13) for the data listed in Table 1 . The variables $\mathbf{x}, \mathbf{y}$, and $\mathbf{z}$ are assigned $R$, and mean particle size $D_{50}$, respectively. The calculated covariance matrices are:

$$
\begin{aligned}
\Gamma_{\min } & =\left[\begin{array}{ccc}
0.0112 & -0.013 & -0.017 \\
-0.013 & 0.0409 & 0.0004 \\
-0.017 & 0.0004 & 0.5701
\end{array}\right] \\
\Gamma_{\max } & =\left[\begin{array}{ccc}
0.0393 & -0.03 & -0.032 \\
-0.03 & 0.0425 & 0.004 \\
-0.032 & 0.004 & 0.5158
\end{array}\right]
\end{aligned}
$$

In both matrices, the covariance between the limiting void ratio and roundness or mean particle size is negative, indicating an increase of limiting void ratios with a decrease of particle roundness or mean

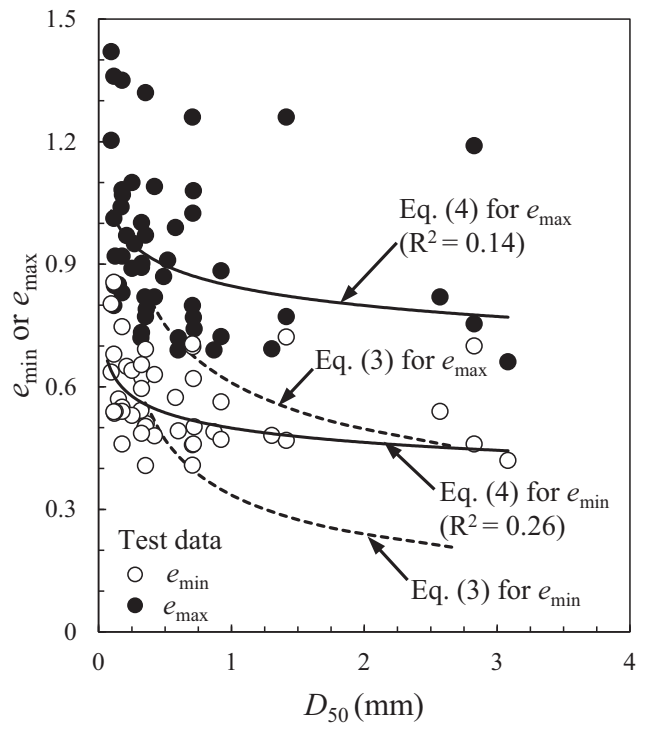

Fig. 5. Predicted limiting void ratios (solid and dashed lines) versus mean particle size, compared with the measured values from uniform sand samples, listed in Table. 1.

particle size. The magnitude of the covariance indicates the strength of dependency between the two variables. However, this value is not easy to interpret. Therefore, it is common to use the correlation coefficient (i.e. the normalized version of covariance), which ranges from 0 to 1 , where 0 indicates complete independency, and 1 indicates complete dependency between the two variables.

The correlation coefficient $\rho(\mathbf{x}, \mathbf{y})$ of any two random variables can be calculated as:

$\rho(\mathbf{x}, \mathbf{y})=\frac{\operatorname{Cov}(\mathbf{x}, \mathbf{y})}{\sigma(\mathbf{x}) \sigma(\mathbf{y})}$

where $\sigma(\mathbf{x})$ and $\sigma(\mathbf{y})$ are the standard deviations of variables $\mathbf{x}$ and $\mathbf{y}$, respectively.

The correlation matrix $\Omega$ of the three-variable set $(\mathbf{x}, \mathbf{y}, \mathbf{z})$ is defined as:

$\Omega=\left[\begin{array}{lll}\rho(\mathbf{x}, \mathbf{x}) & \rho(\mathbf{x}, \mathbf{y}) & \rho(\mathbf{x}, \mathbf{z}) \\ \rho(\mathbf{y}, \mathbf{x}) & \rho(\mathbf{y}, \mathbf{y}) & \rho(\mathbf{y}, \mathbf{z}) \\ \rho(\mathbf{z}, \mathbf{x}) & \rho(\mathbf{z}, \mathbf{y}) & \rho(\mathbf{z}, \mathbf{z})\end{array}\right]$

The correlation matrices $\Omega_{\min }$ and $\Omega_{\max }$ are calculated using Eqs. (15) and (16) for the data listed in Table 1, based on the covariance matrices $\Gamma_{\min }$ and $\Gamma_{\max }$. The variables $\mathbf{x}, \mathbf{y}$, and $\mathbf{z}$ are assigned to the limiting void ratio, particle roundness $R$, and mean particle size $D_{50}$, respectively. The calculated correlation matrices are:

$\Omega_{\min }=\left[\begin{array}{ccc}1 & -0.626 & -0.213 \\ -0.626 & 1 & 0.003 \\ -0.213 & 0.003 & 1\end{array}\right]$
$\Omega_{\max }=\left[\begin{array}{ccc}1 & -0.742 & -0.227 \\ -0.742 & 1 & 0.027 \\ -0.227 & 0.027 & 1\end{array}\right]$

where $\Omega_{\min }$ and $\Omega_{\max }$ are the correlation matrices of the set $\left(e_{\min }, R\right.$, $\left.D_{50}\right)$ and the set $\left(e_{\max }, R, D_{50}\right)$, respectively.

In both matrices, the correlation coefficients between the limiting void ratio and particle roundness or between the limiting void ratio and particle size are negative, indicating an increase of the limiting void 

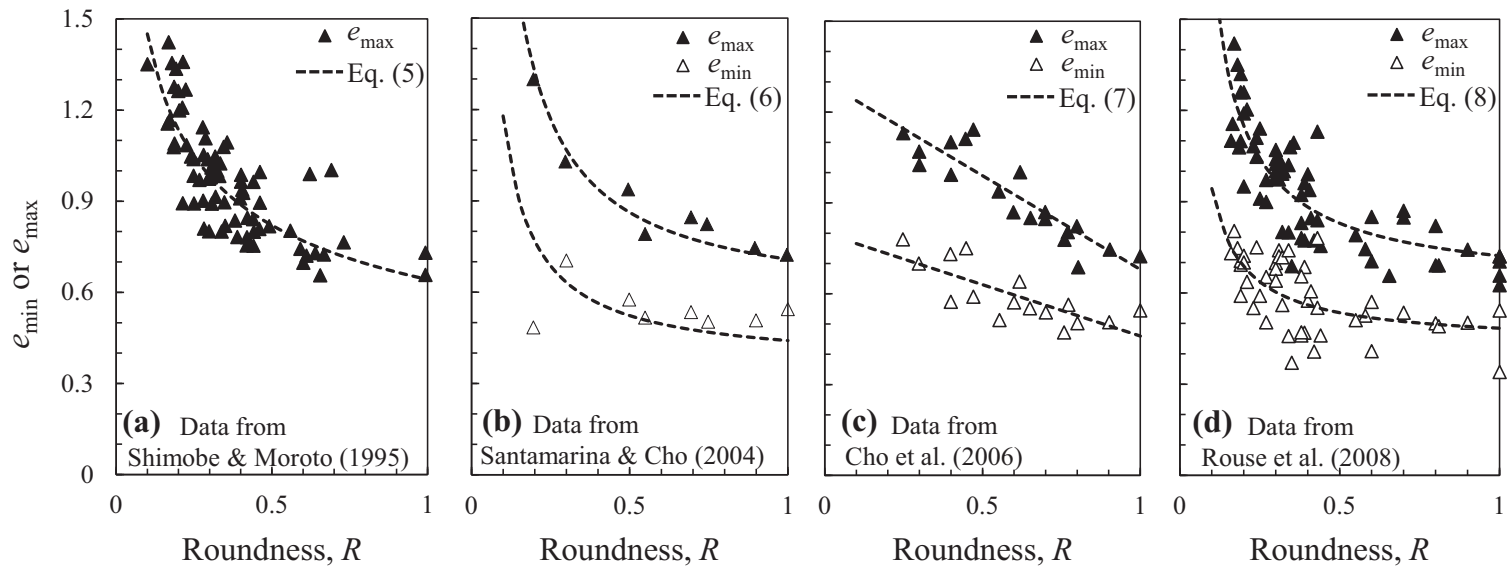

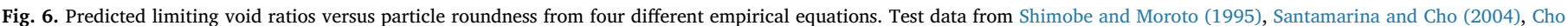
et al. (2006), and Rouse et al. (2008).

ratios with a decrease of particle roundness or mean particle size. The magnitude of the correlation coefficient indicates the degree of correlation between two random variables. For the minimum void ratio, the magnitude of correlation coefficient between $R$ and $e_{\min }$ is 0.626 , which is stronger than that between $D_{50}$ and $e_{\min }$, which is 0.213 . Similarly, the magnitude of correlation coefficient between $e_{\max }$ and $R$ is 0.742 , while it is 0.227 between $e_{\max }$ and $D_{50}$. Therefore, the correlation between $R$ and the limiting void ratios is stronger than that between $D_{50}$ and the limiting void ratios.

The magnitude of the correlation coefficient between $R$ and $D_{50}$ is 0.003 in the correlation matrix for minimum void ratio $\Omega_{\min }$ and is 0.027 in the correlation matrix for maximum void ratio $\Omega_{\max }$. These small values indicate that particle roundness and particle size have very weak correlation. Therefore, $R$ and $D_{50}$ can be considered as two independent variables. This independency was also supported by Das (2007), who found that there is no correlation between $R$ and $D_{50}$ for sands from six different sources.

Since the variables, $R$ and $D_{50}$, are correlated with the limiting void ratio, but uncorrelated with each other, the limiting void ratio can be considered as the outcome variable and $R$ and $D_{50}$ can be considered as two independent predictive variables. We propose a multi-variable equation that expresses the limiting void ratio $\left(e_{\max }\right.$ or $\left.e_{\min }\right)$ as a function of the two variables $R$ and $D_{50}$. The proposed two-variable equation is as follows:

$e_{\lim }=c_{\lim } \cdot R^{\alpha_{\lim }} \cdot D^{\beta_{\lim }}$

where $R$ and $D$ are both dimensionless. The normalized particle size $D$ is defined as $D=D_{50} / D_{\text {ref }}$, with $D_{\text {ref }}=1 \mathrm{~mm}$. The magnitude of $D$ and $D_{50}$ are identical. The subscript lim represents that the variable is associated with either $e_{\min }$ or $e_{\max }$. The coefficient $c_{\text {lim }}$ is a dimensionless constant, which is equal to the limiting void ratio of $1 \mathrm{~mm}$ sized sphere packing (i.e. $R=1$ and $D_{50}=1$ ). The constants $\alpha_{\lim }$ and $\beta_{\text {lim }}$ are two model parameters that replicate the effects of $R$ and $D_{50}$ on the limiting void ratio. The three constants $c_{\lim }, \alpha_{\lim }$ and $\beta_{\lim }$ take different values for the two different cases of $e_{\min }$ or $e_{\max }$.

The constants of Eq. (18), $\alpha_{\text {lim }}, \beta_{\text {lim }}$, and $c_{\text {lim }}$ are determined for the limiting void ratio $\left(e_{\min }\right.$ or $\left.e_{\max }\right)$ by a multi-variable regression analysis, using the experimental data listed in Table 1 . The equations are as follows:

$e_{\min }=0.413 \cdot R^{-0.291} \cdot D^{-0.043}$
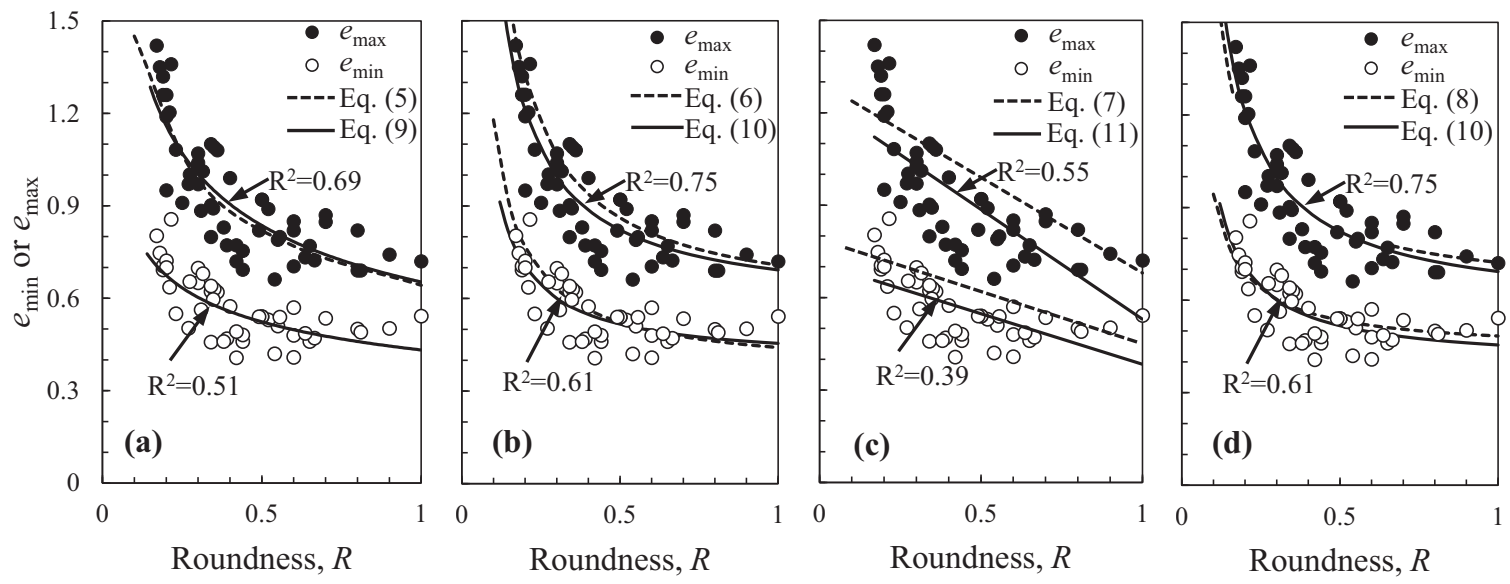

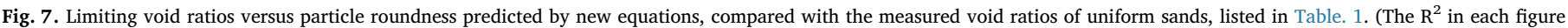
corresponds to the two solid lines). 


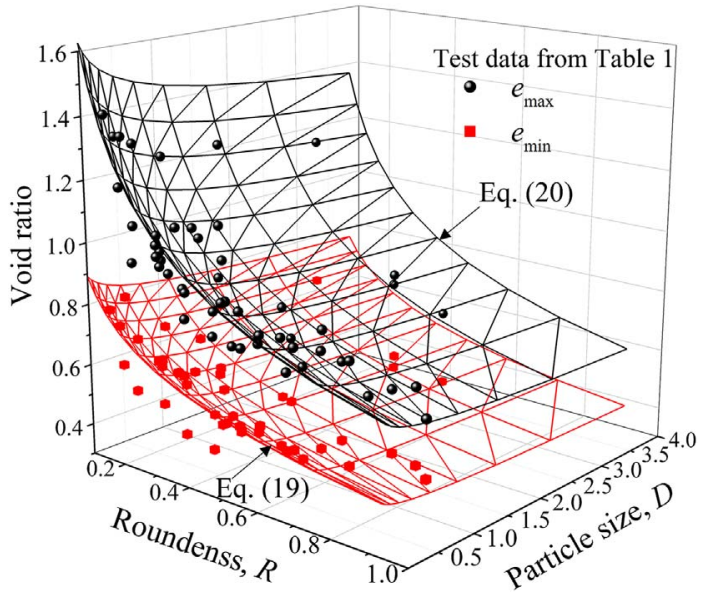

Fig. 8. Three-dimensional representation of Eq. (19) for $e_{\max }$ and Eq. (20) for $e_{\min }$ in linear space.

$e_{\max }=0.619 \cdot R^{-0.372} \cdot D^{-0.048}$

Eqs. (19) and (20) are plotted as two curved surfaces in a threedimensional $\left(D, R, e_{\text {lim }}\right)$ space as shown in Fig. 8. The coefficient of multiple determination $\mathrm{R}^{2}$ is 0.62 for $e_{\min }$ and 0.76 for $e_{\max }$.

Eq. (18) can be linearized by taking logarithm of both sides of the equation:

$\log e_{\lim }=\alpha_{\lim } \log R+\beta_{\lim } \log D+\log c_{\lim }$

Thus, Eqs. (19) and (20) can be expressed as follows:

$\log e_{\min }=-0.291 \log R-0.043 \log D+\log 0.413$

$\log e_{\max }=-0.372 \log R-0.048 \log D+\log 0.619$

Eqs. (22) and (23) are identical to Eqs. (19) and (20), although they are expressed in different forms. Eqs. (22) and (23) are plotted in a three-dimensional $\log$ arithmic space $(\log D, \log R, \log e)$ in Fig. 9 .

In Eqs. (22) and (23), the magnitude of $\alpha_{\text {lim }}$, associated with $R$, is much larger than the magnitude of $\beta_{\text {lim }}$, associated with $D$ (i.e., $0.291>0.043$ and $0.372>0.048)$. This indicates that particle roundness $(R)$ has more influence than particle size $(D)$ on the value of limiting void ratio.

To depict the the coupled effects of particle roundness and particle size on limiting void ratios, the two planes in the three-dimensional space calculated from Eqs. (22) and (23) are projected onto the plane of limiting void ratios versus $D$. The contour lines for various values of roundness $R$ are plotted for $e_{\min }$ and $e_{\max }$ in Fig. 10a and b, respectively. The corresponding experimental data (from Table 1) are shown by symbols. It can be seen from these two graphs that the limiting void ratios decrease with an increase of particle size, regardless of the particle roundness. For a given particle size, the limiting void ratios decrease with the increase of particle roundness.

Similarly, the two 3-dimensional planes shown in Fig. 8 are projected onto the plane of limiting void ratios versus $R$, with the contour lines for various values of $D$ shown in Fig. $11 \mathrm{a}$ and b. The experimental data from Table 1 are shown with symbols. It can be seen from these graphs that the limiting void ratios decrease with an increase of roundness. For a given particle roundness, the limiting void ratios decrease with the increase of particle size. The width of the particle size variation band in Fig. 11 is much smaller than the particle roundness variation band in Fig. 10. This indicates that the limiting void ratios are strongly correlated with particle roundness, whereas they are weakly

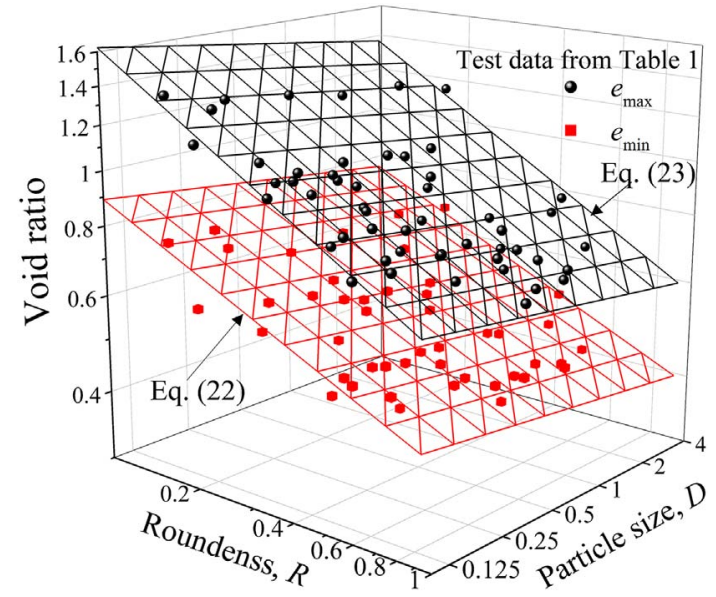

Fig. 9. Three-dimensional representation of Eqs. (22) and (23) in logarithmic space.

correlated with particle size.

7. Comparison between the proposed multi-variable relationship and existing single-variable equations

The following examples illustrate the advantage of the proposed multi-variable equation over the single-variable equations.

\subsection{Proposed multi-variable relationship compared to the single-variable} equation with particle size as the predictive variable

First, we compare the performance of the proposed multi-variable equation with Eq. (4) that uses particle size as the single predictive variable. It has been shown in Fig. 5 that Eq. (4) is in poor agreement with the measured data and is not a suitable predictive equation. Conversely, the proposed multi-variable equation is a suitable predictive equation based on its high value of $\mathrm{R}^{2}$, which is 0.62 for $e_{\min }$ and 0.76 for $e_{\max }$ as shown in Fig. 8. A comparison of the measured and predicted results between the proposed multi-variable equation and the single-variable equation for angular sand is shown in Fig. 12. The two dashed lines for $e_{\min }$ and $e_{\max }$ are computed from the single-variable equation (Eq. (4)). The predicted values from the multi-variable equations (Eqs. (19) and (20)) are shown with cross symbols. The two zones for $e_{\min }$ and $e_{\max }$ between the solid lines are computed from the multivariable equations (Eqs. (19) and (20)) for particle roundness of $R=0.17$ and 0.20 . The multi-variable equations are in better agreement with the test results compared to the single-variable equation.

\subsection{Proposed multi-variable relationship compared to the single-variable} equation with particle roundness as the predictive variable

Among the three single-variable equations, which take particle roundness as a predictive variable (Eqs. (9) to (11)), Eq. (10) has the highest value of $\mathrm{R}^{2}$, as shown in Fig. 7. Here, we compare the performance of the multi-variable equations (Eqs. (19) and (20)) with the single-variable equation (Eq. (10)). It is noted that $\mathrm{R}^{2}$ alone cannot be used as a meaningful comparison of models with different numbers of independent variables (Richard, 1994). For a meaningful comparison between the two models, we use the Mean Absolute Percentage Error (MAPE).

For the comparison, two groups of samples are selected from Table 1 

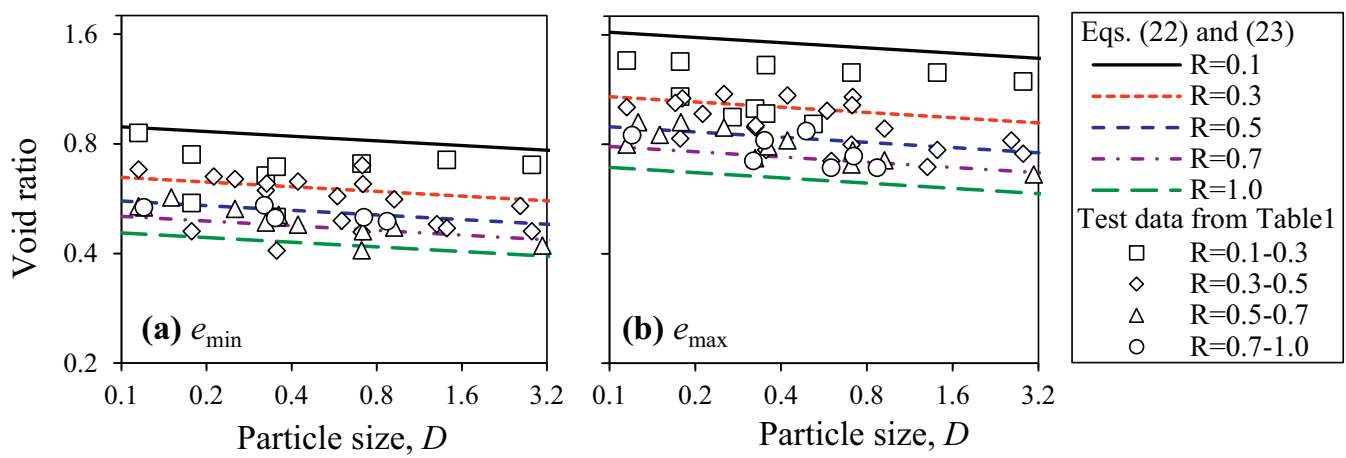

Fig. 10. Projection of Eqs. (22) and (23) on the 2-D plane of limiting void ratios versus mean particle size.
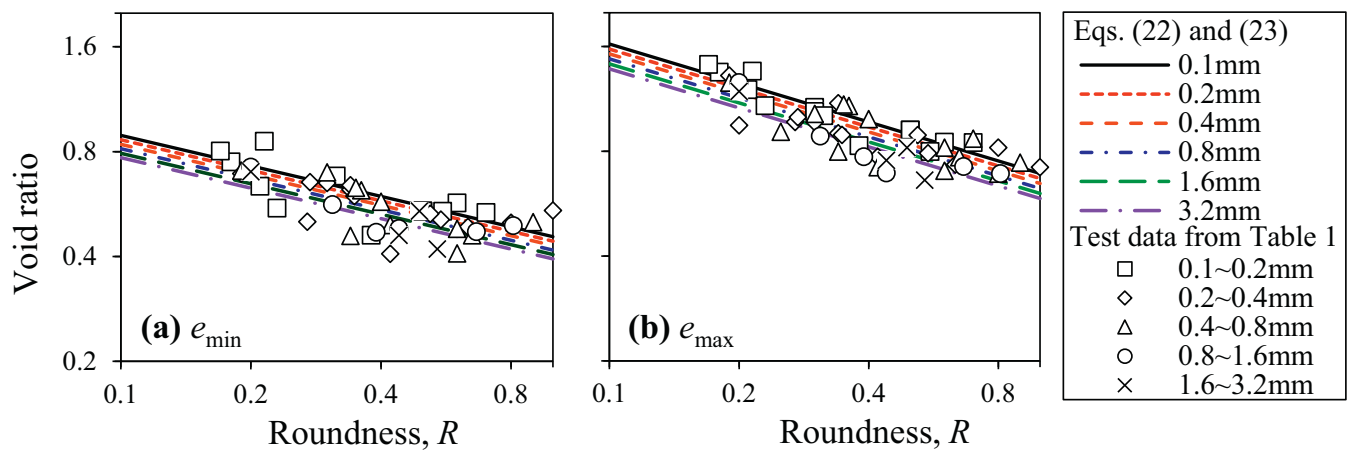

Fig. 11. Projection of Eqs. (22) and (23) on the 2-D plane of limiting void ratios versus particle roundness.

based on their mean particle size: (a) small particle size samples with $\mathrm{D}_{50}$ ranging from 0.075 to $0.15 \mathrm{~mm}$, and (b) large particle size samples with $\mathrm{D}_{50}$ ranging from 1.0 to $3.5 \mathrm{~mm}$.

The predictions of $e_{\min }$ using the single-variable equation Eq. (10) are shown by the dashed lines in Fig. 13a and b. The test data are shown with symbols. It can be seen in Fig. 13a that Eq. (10) overpredicts the test results for samples with large particles, whereas Eq. (10) underpredicts the test results for samples with small particles (Fig. 13b).

The proposed multi-variable equation, Eq. (19), can predict minimum void ratio based on particle roundness for various values of

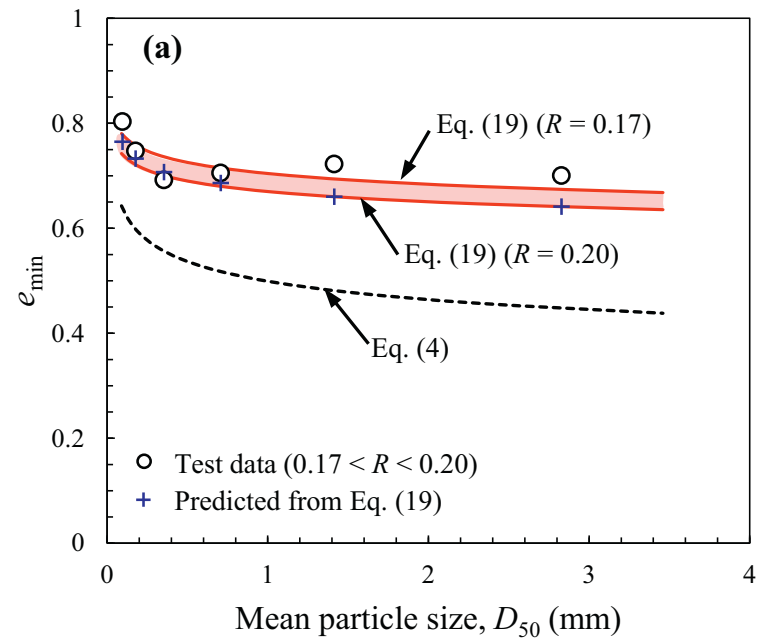

mean particle size. The predicted values from Eq. (19) are shown with cross symbols. The two solid lines in Fig. 13a are predicted based on mean particle sizes of $0.075 \mathrm{~mm}$ and $0.15 \mathrm{~mm}$. The shaded zone between the two solid lines represents the predicted range for small particle size samples. In Fig. 13b, the shaded zone between the two solid lines for $1.0 \mathrm{~mm}$ and $3.5 \mathrm{~mm}$ represents the range of predicted values for large particle size samples. The predictions from the multivariable equation tend to fit the experimental data better than predictions from the single-variable equation (Eq. (10)). The mean absolute percentage error (MAPE) between predictions and measurments are

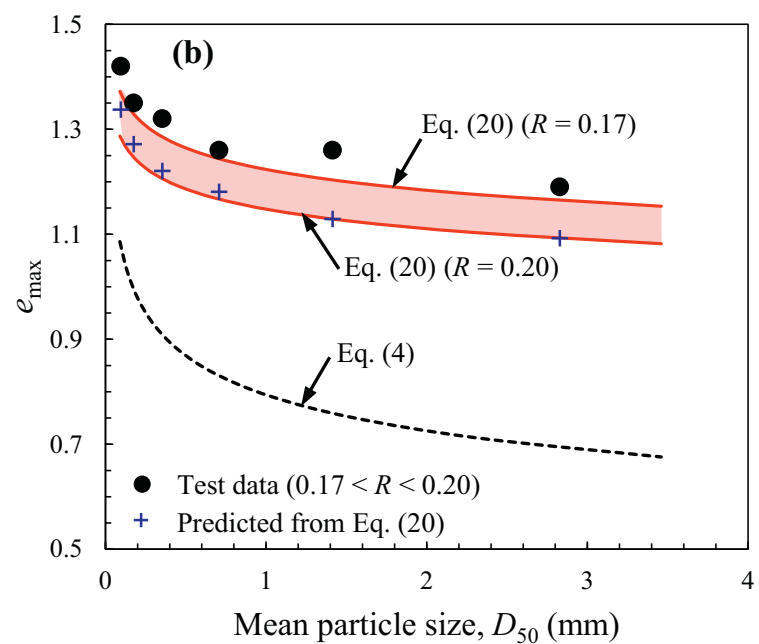

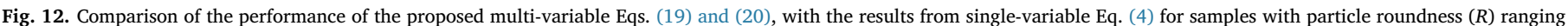
from 0.17 to 0.20 (Test data selected from Table 1). 

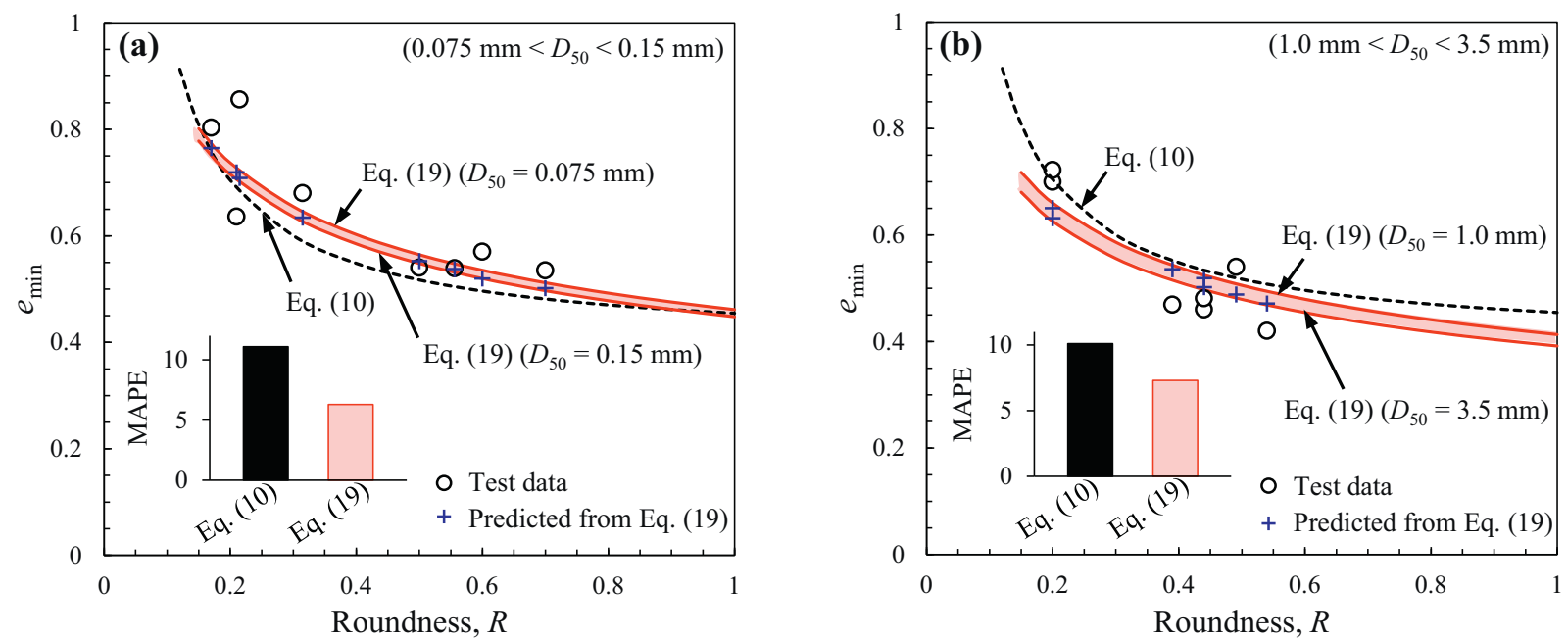

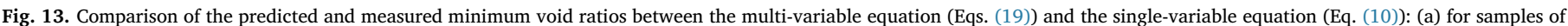
small particle sizes, and (b) for samples of large particle sizes (Test data from Table 1).

also shown for each relationship in Fig. 13.

The predictions of $e_{\max }$ using the single-variable equation (Eq. (10)) are shown by the dashed lines in Fig. 14a and b. The predicted values from Eq. (20) are shown with cross symbols. The test data for these two groups of sand samples are shown with symbols. It can be seen from Fig. 14a and Fig. 14b that Eq. (10) underpredicts the test results for samples with small particles, while it overpredicts the test results for samples with large particles.

Fig. 14a shows the predicted range of maximum void ratio for samples with small particles. Fig. $14 \mathrm{~b}$ shows the same range for samples with large particles. The prediction from the multi-variable equation tends to fit the experimental data better than the single-variable equation. The mean absolute percentage error (MAPE) from predictions are also shown for each equation in Fig. 14.

From the comparisons of the mean absolute percentage error (MAPE) in all cases shown in Figs. 13 and 14, the percentage error is $7.4 \%$ to $11.5 \%$ for single-variable equations and $4.9 \%$ to $8.5 \%$ for multi-variable equations. In terms of void ratio, the difference between

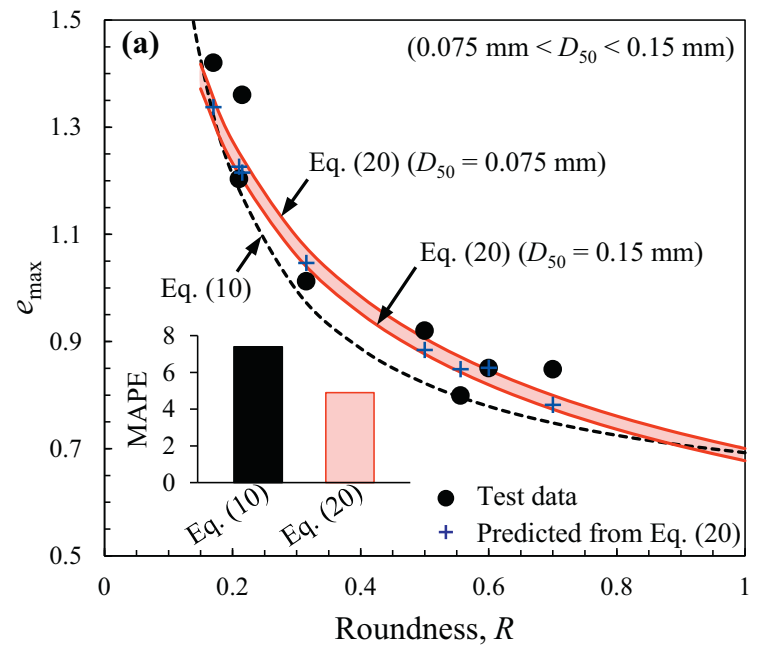

the two models is in the range of 0.03 to 0.08 . This corresponds to approximately $5 \%$ to $20 \%$ improvement in the prediction of relative density when using the proposed multi-variable equations, which leads to a notable difference in the estimated strength and compressibility of soils (U.S. Navy, 1982).

It is noted that the proposed multi-variable equations can only be used to predict the limiting void ratios of uniform sands. Although the granular soil encountered in geotechnical engineering are more likely to be widely graded, it is not uncommon to encounter uniform sand, for example, the clean sand deposit in the Northern Lower-Peninsula region of Michigan in the United States (Muszynski, 2006). The limiting void ratios predicted by the multi-variable equations are useful in the design of compaction specifications for a natural sand or for an imported backfill of a retaining structure in order to properly support heavy loads. The predicted limiting void ratios can also be used in the recently developed models to estimate the compressibility of sands (Meidani et al., 2017).

Obviously, the proposed equations cannot be applied directly to the

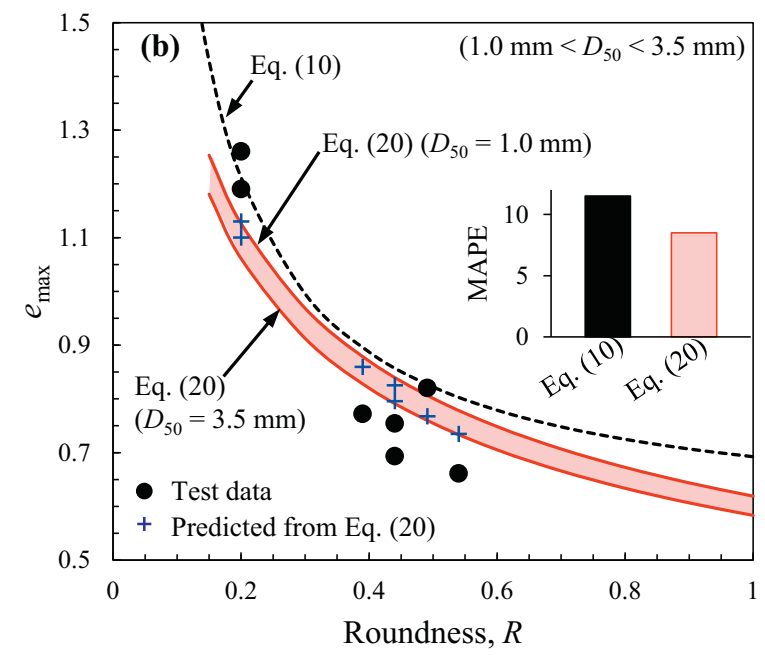

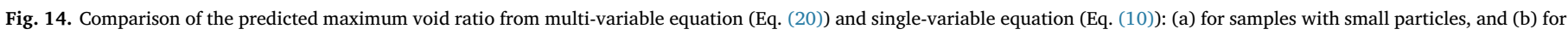
samples with large particles (Test data selected from Table 1). 
soil with a broader range of particle sizes. However, as indicated in many analytical packing models, the limiting void ratio of a multi-sized packing can be derived from the limiting void ratios of mono-sized packings (Chang et al., 2015, 2017; De Larrard, 1999; Dewar, 1999; Furnas, 1931; Goltermann et al., 1997; Kwan et al., 2013; Powers, 1968; Stovall et al., 1986; Westman and Hugill, 1930; Yu and Standish, 1988). In general, a multi-sized packing is treated as a mixture of 10-12 size classes of particles. The limiting void ratio of a mono-sized packing for each size class particles is required as input data for the analytical packing models in order to predict the limiting void ratio of the multisized particle packing. Therefore, the multi-variable equation developed in this study can serve as an aid to provide the input data for the analytical packing models and obtain an estimation of the limiting void ratios of multi-sized particle packings.

\section{Conclusions}

Experimental data have shown that morphological characteristics of sand particles (i.e. particle size and particle roundness) affect the minimum and maximum void ratios of uniform sands. In this paper, we proposed two multi-variable equations to predict minimum and maximum void ratios of uniform sands from their particle size and particle shape.

The statistical analysis on this dataset showed that the correlation between particle roundness and the limiting void ratios of uniform sands is relatively strong (correlation coefficient is 0.62 to 0.75 ). The correlation between particle size and the limiting void ratios of uniform sands is, however, weak (correlation coefficient is 0.21 to 0.23 ). There is nearly no correlation between particle size and particle roundness for uniform sands selected in this study (correlation coefficient is $<0.03$ ). Therefore, particle size and particle roundness were considered as two independent predictive variables, and the limiting void ratios were considered as the dependent outcome variables.

The multi-variable statistical analysis showed that the relationship between the limiting void ratios and the two morphological characteristics of sand particles are two parallel planes in a three-dimensional logarithmic space made of particle size, particle roundness and limiting void ratio.

The comparison between the experimental results and predicted values showed:

(1) The single-variable equation with particle size as a predictive variable is not suitable for application. The multi-variable equation is a suitable predictive equation.

(2) The single-variable equation with particle roundness as a predictive variable was in reasonable agreement with the measured data. However, it over-predicted the limiting void ratios for samples with large particles, but under-predicted the limiting void ratios for samples with small particles. The prediction error of the proposed multi-variable equation is reduced to about $2 / 3$ of the prediction error of the single-variable equation. In terms of predicted void ratio, the difference between the two models is in the range of $0.03-0.07$. This corresponds to approximately $5 \%-20 \%$ in relative density, which leads to a notable difference in the estimated strength and compressibility of sands.

The proposed multi-variable equations can be directly used to predict the limiting void ratios of uniform sands encountered in geotechnical engineering projects. The predicted limiting void ratios are useful in the design of compaction specifications in order to properly support heavy loads. The multi-variable equation developed in this study can be used together with an analytical packing model (e.g. Chang et al., 2015, 2017; De Larrard, 1999; Yu and Standish, 1988) for a better estimation of the limiting void ratios of multi-sized particle packings.

\section{Acknowledgements}

This work was supported by the National Science Foundation of the United States through grant number CMMI-1537491.

\section{References}

Aberg, B., 1992. Void ratio of noncohesive soils and similar materials. J. Geotech. Eng. 118, 1315-1334. http://dx.doi.org/10.1061/(ASCE)0733-9410(1992)118:9(1315).

Allen, T., 1997. Particle size measurement. In: Powder Sampling and Particle Size Measurment, 5th ed. vol. 1 Chapman \& Hall, London.

ASTM D422-63, 2007. Standard Test Method for Particle-Size Analysis of Soil. ASTM International, West Conshohocken, PA.

ASTM D4253-00, 2006. Standard test methods for maximum index density and unit weight of soils using a vibratory table. In: Annual Book of ASTM Standards. ASTM International, West Conshohocken, PA, pp. 1-15. http://dx.doi.org/10.1520/D425300R06.

ASTM D4254-00, 2006. Standard test methods for minimum index density and unit weight of soils and calculation of relative density. In: Annual Book of ASTM Standards. ASTM International, West Conshohocken, PA, pp. 1-9. http://dx.doi.org/ 10.1520/D4254-00R06E01.1.3.

Bandini, P., Sathiskumar, S., 2009. Effects of silt content and void ratio on the saturated hydraulic conductivity and compressibility of sand-silt mixtures. J. Geotech. Geoenviron. Eng. 135, 1976-1980. http://dx.doi.org/10.1061/(ASCE)GT.19435606.0000177 .

Bareither, C.a., Edil, T.B., Benson, C.H., Mickelson, D.M., 2008. Geological and physical factors affecting the friction angle of compacted sands. J. Geotech. Geoenviron. Eng. 134, 1476-1489. http://dx.doi.org/10.1061/(ASCE)1090-0241(2008)134:10(1476).

Barrett, P.J., 1980. The shape of rock particles, a critical review. Sedimentology 27, 291-303. http://dx.doi.org/10.1111/j.1365-3091.1980.tb01179.x.

Belkhatir, M., Schanz, T., Arab, A., 2013. Effect of fines content and void ratio on the saturated hydraulic conductivity and undrained shear strength of sand-silt mixtures. Environ. Earth Sci. 70, 2469-2479. http://dx.doi.org/10.1007/s12665-013-2289-z.

Blaker, Ø., Lunne, T., Vestgården, T., Krogh, L., Thomsen, N.V., Powell, J.J.M., Wallace, C.F., 2015. Method dependency for determining maximum and minimum dry unit weights of sands. In: Meyer, Vaughan (Ed.), Frontiers in Offshore Geotechnics III. Taylor \& Francis Group, London, pp. 1159-1166. http://dx.doi.org/10.1201/ b18442-174.

Bobei, D.C., Lo, S.R., Wanatowski, D., Gnanendran, C.T., Rahman, M.M., 2009. Modified state parameter for characterizing static liquefaction of sand with fines. Can. Geotech. J. 46, 281-295. http://dx.doi.org/10.1139/T08-122.

Chang, C.S., Wang, J.-Y., Ge, L., 2015. Modeling of minimum void ratio for sand-silt mixtures. Eng. Geol. 196, 293-304. http://dx.doi.org/10.1016/j.enggeo.2015.07. 015.

Chang, C.S., Deng, Y., Yang, Z., 2017. Modeling of minimum void ratio for granular soil with effect of particle size distribution. J. Eng. Mech. 143, 4017060. http://dx.doi. org/10.1061/(ASCE)EM.1943-7889.0001270.

Cho, G.-C., Dodds, J., Santamarina, J.C., 2006. Particle shape effects on packing density, stiffness, and strength: natural and crushed sands. J. Geotech. Geoenviron. Eng. 132, 591-602. http://dx.doi.org/10.1061/(ASCE)1090-0241(2006)132:5(591).

Cox, M.R., Budhu, M., 2008. A practical approach to grain shape quantification. Eng. Geol. 96, 1-16. http://dx.doi.org/10.1016/j.enggeo.2007.05.005.

Cubrinovski, M., Ishihara, K., 2002. Maximum and minimum void ratio characteristics of sands. Soils Found. 42, 65-78. http://dx.doi.org/10.3208/sandf.42.6_65.

Das, N., 2007. Modeling Three-Dimensional Shape of Sand Grains Using Discrete Element Method. PhD Thesis. University of South Florida.

De Larrard, F., 1999. Concrete Mixture Proportioning: A Scientific Approach, The Effects of Brief Mindfulness Intervention on Acute Pain Experience: An Examination of Individual Difference. E \& FN Spon, London. http://dx.doi.org/10.1017/ CBO9781107415324.004.

Dewar, J.D., 1999. Computer Modelling of Concrete Mixtures. E \& FN Spon, London.

Diepenbroek, M., Bartholomä, A., Ibbeken, H., 1992. How round is round? A new approach to the topic "roundness" by Fourier grain shape analysis. Sedimentology 39, 411-422. http://dx.doi.org/10.1111/j.1365-3091.1992.tb02125.x.

Edil, T.B., Krizek, R.J., Zelasko, J.S., 1975. Effect of grain characteristics on packing of sands. In: Proceedings of Istanbul Conf on Soil Mech and Found Eng. pp. 46-54.

Fuggle, A.R., Roozbahani, M.M., Frost, J.D., 2014. Size effects on the void ratio of loosely packed binary particle mixtures. In: Geo-Congress 2014 Technical Papers. American Society of Civil Engineers, Reston, VA, pp. 129-138. http://dx.doi.org/10.1061/ 9780784413272.014

Furnas, C.C., 1931. Grading aggregates I: mathematical relations for beds of broken solids of maximum density. Ind. Eng. Chem. 23, 1052-1058. http://dx.doi.org/10.1021/ ie50261a017.

Goltermann, P., Johansen, V., Palbøl, L., 1997. Packing of aggregates: an alternative tool to determine the optimal aggregate mix. ACI Mater. J. 94, 435-443.

Hyslip, J.P., Vallejo, L.E., 1997. Fractal analysis of the roughness and size distribution of granular materials. Eng. Geol. 48, 231-244. http://dx.doi.org/10.1016/S00137952(97)00046-X.

Japanese Geotechnical Society, 2000. Test method for minimum and maximum densities of sand. In: Soil Testing Standards, pp. 136-138 (in Japanese).

Kolbuszewski, J.J., 1948. An experimental study of the maximum and minimum properties of sands. In: Proceedings of the Second International Conference on Soil Mechanics and Foundation Engineering, pp. 158-165 (Rotterdam).

Krumbein, W.C., 1941. Measurement and geological significance of shape and roundness 
of sedimentary particles. J. Sediment. Petrol. 11, 64-72.

Kwan, A.K.H., Chan, K.W., Wong, V., 2013. A 3-parameter particle packing model incorporating the wedging effect. Powder Technol. 237, 172-179. http://dx.doi.org/ 10.1016/j.powtec.2013.01.043.

Meidani, M., Chang, C.S., Deng, Y., 2017. On active and inactive voids and a compression model for granular soils. Eng. Geol. 222, 156-167. http://dx.doi.org/10.1016/j. enggeo.2017.03.006.

Miura, K., Maiida, K., Furukawa, M., Toki, S., 1997. Physical characteristics of sands with different primary properties. Soils Found. 37, 53-64.

Mulilis, J.P., Arulanandan, K., Mitchell, J.K., Chan, C.K., Seed, H.B., 1977. Effects of sample preparation on sand liquefaction. J. Geotech. Eng. Div. 103, 91-108. http:// dx.doi.org/10.1016/0148-9062(77)90060-2.

Muszynski, M.R., 2006. Determination of maximum and minimum densities of poorly graded sands using a simplified method. Geotech. Test. J. 29, 263-272. http://dx.doi. org/10.1520/GTJ12591.

U.S. Navy, 1982. Soil Mechanics, NAVFAC Design Manual 7.1. Navy Facilities Engineering Command, Arlington, VA.

Norris, G.M., 1977. The Drained Shear Strength of Uniform Quartz Sand as Related to Particle Size and Natural Variation in Particle Shape and Surface Roughness. Ph.D. thesis. University of California, Berkeley.

Okonta, F.N., 2015. Effect of grading category on the roundness of degraded and abraded railway quartzites. Eng. Geol. 193, 231-242. http://dx.doi.org/10.1016/j.enggeo. 2015.03.018.

Patra, C.R., Sivakugan, N., Das, B.M., Rout, S.K., 2010. Correlations for relative density of clean sand with median grain size and compaction energy. Int. J. Geotech. Eng. 4, 195-203. http://dx.doi.org/10.3328/IJGE.2010.04.02.195-203.

Peters, J.F., Berney, E.S., 2010. Percolation threshold of sand-clay binary mixtures. J. Geotech. Geoenviron. Eng. 136, 310-318. http://dx.doi.org/10.1061/(ASCE)GT. 1943-5606.0000211.

Powers, M.C., 1953. A new roundness scale for sedimentary particles. J. Sediment. Petrol. 23, 117-119. http://dx.doi.org/10.1306/d4269567-2b26-11d7-8648000102c1865d.

Powers, T.C., 1968. The Properties of Fresh Concrete. John Wiley \& Sons, New York.

Richard, A.-S., 1994. Model comparisons and R2. Am. Stat. 48, 113-117.

Rouse, P.C., Fannin, R.J., Shuttle, D.A., 2008. Influence of roundness on the void ratio and strength of uniform sand. Géotechnique 58, 227-231. http://dx.doi.org/10.1680/ geot.2008.58.8.681.

Rout, S.K., 2009. Prediction of Relative Density of Sand with Particular Reference to Compaction Energy. National Institute of Technology, Rourkela.

Santamarina, J.C., Cho, G.C., 2004. Soil behaviour: the role of particle shape. In: Jardine,
R.J., Potts, D.M., Higgins, K.G. (Eds.), Advances in Geotechnical Engineering: Proceedings of the Skempton Conference. vol. 1. Thomas Telford, London, pp. 604-617.

Selig, E., Ladd, R., 1973. Evaluation of relative density measurements and applications. In: Evaluation of Relative Density and Its Role in Geotechnical Projects Involving Cohesionless Soils. ASTM International, West Conshohocken, PA (487-18). https:// doi.org/10.1520/STP37891S.

Shimobe, S., Moroto, N., 1995. A new classification chart for sand liquefaction. In: Ishihara (Ed.), Proc. 1st Int. Conf. on Earthquake Geotechnical Engineering, pp. 315-320 (Tokyo).

Stovall, T., de Larrard, F., Buil, M., 1986. Linear packing density model of grain mixtures. Powder Technol. 48, 1-12. http://dx.doi.org/10.1016/0032-5910(86)80058-4.

Tafesse, S., Fernlund, J.M.R., Bergholm, F., 2012. Digital sieving-Matlab based 3-D image analysis. Eng. Geol. 137-138, 74-84. http://dx.doi.org/10.1016/j.enggeo.2012.04. 001.

Tavenas, F., Ladd, R., La Rochelle, P., 1973. Accuracy of relative density measurements: results of a comparative test program. In: Evaluation of Relative Density and Its Role in Geotechnical Projects Involving Cohesionless Soils. ASTM International, West Conshohocken, PA, pp. 18-43. http://dx.doi.org/10.1520/STP37862S.

Uday, K.V., Padmakumar, G.P., Singh, D.N., 2013. Some studies on morphology of the coarse-grained soils. Eng. Geol. 152, 48-55. http://dx.doi.org/10.1016/j.enggeo. 2012.10.001.

Vaid, Y., Negussey, D., 1988. Preparation of reconstituted sand specimens. In: Donaghe, R.T., Chaney, R.C., Silver, M.L. (Eds.), American Society for Testing and Materials. ASTM International, Philadelphia, pp. 405-417. http://dx.doi.org/10.1520/ STP29090S.

Wadell, H., 1935. Volume, shape, and roundness of quartz particles. J. Geol. 43, 250-280.

Westman, A.E.R., Hugill, H.R., 1930. The packing of particles. J. Am. Ceram. Soc. 13, 767-779. http://dx.doi.org/10.1111/j.1151-2916.1930.tb16222.x.

Youd, T.L., 1973. Factors controlling maximum and minimum densities of sands. In: Evaluation of Relative Density and Its Role in Geotechnical Projects Involving Cohesionless Soils, STP 523. ASTM International, West Conshohocken, PA, pp. 98-112. http://dx.doi.org/10.1520/STP37866S.

Yu, A.B., Standish, N., 1988. An analytical-parametric theory of the random packing of particles. Power Technol. 55, 171-186. http://dx.doi.org/10.1016/0032-5910(88) 80101-3.

Zheng, J., Hryciw, R.D., 2016. Index void ratios of sands from their intrinsic properties. J. Geotech. Geoenviron. Eng. 142, 6016019. http://dx.doi.org/10.1061/(ASCE)GT. 1943-5606.0001575. 